\title{
GASPAR BECERRA, ESCULTOR O TRACISTA. LA DOCUMENTACIÓN TESTAMENTARIA DE SU VIUDA, PAULA VELÁZQUEZ
}

\author{
POR \\ MANUEL ARIAS MARTÍNEZ \\ Museo Nacional de Escultura
}

\begin{abstract}
The recent discovery of the last will of Paula Velázquez, Gaspar Becerra's widow, dated in 1568, provides precise information about Becerra's artistic personality, professional and family relationships. The contents of the last will enlighten Becerra's activity as painter and sketcher of important sculpture programms, managing as well a woodcarvers workshop, which spread the italian formal innovations previously introduced by Becerra around Spain during the Counter-reform era.
\end{abstract}

La trascendencia de Gaspar Becerra para la historia de las formas artísticas hispanas de la segunda mitad del XVI ha sido fundamental. La renovación estética que supone su aportación del manierismo romano a nuestro país condiciona la evolución formal de la pintura y la escultura desde 1560 hasta el primer cuarto del siglo XVII en un amplio radio geográfico, dando lugar a una larga perduración de sus esquemas, perpetuados a través de un fecundo grupo de discípulos, a pesar de su corta vida ${ }^{1}$.

Su estancia en Italia, sumida aún en una nebulosa que cada día se clarifica más, es clave a la hora de explicar la original aportación de sus novedades. Su obra conocida, exclusivamente como fresquista al lado de Vasari o de Volterra, lo disponen en una posición privilegiada para asimilar el arte del momento y lo preparan convenientemente para su regreso a la España de Felipe II. Casado el 15 de julio de 1556 en Roma con Paula Velázquez, hija de Hernando del Torneo y natural de Tordesillas ${ }^{2}$, no tardaría mucho en asentarse en Valladolid, cerca la villa de nacimiento de su mujer, donde firma en 1558 el contrato para llevar a cabo el retablo de la catedral de Astorga, paradigma de su estilo y escuela de un elevado número de artistas que tomarán su repertorio como modelo a seguir.

1 La personalidad artística de Becerra ha sido abordada en artículos como los de Elías Tormo: «Gaspar Becerra (notas varias)», BSEE, Madrid, T. 20, 1912, pp. 65-97; T. 21, 1913, pp. 117-241, Ch. R., Post: The later Renaissance in Castile. A history of Spanish painting, vol. XIV, 1966, pp. 148-180 y Juan José Martín González: «Precisiones sobre Gaspar Becerra», AEA, n 168 , XLII, Madrid, 1969, pp. 327-356. Posteriormente Becerra ha sido objeto de comentarios en obras de carácter general referidas tanto a la pintura y escultura de su época como a las artes en tiempos de Felipe II. El ejemplo más reciente puede ser el libro de Fernando Checa: Felipe II, mecenas de las artes, Madrid, 1992.

2 Cean Bermúdez, J. A.: Diccionario de los más ilustres profesores de las Bellas Artes en España, Madrid, 1800 , Y, pp. 107 y ss.. Es el primero en dar esta noticia sin que sepamos cual es la fuente donde la obtiene. 
Llamado por el rey, quizás como se ha dicho por influencia de su arquitecto Juan Bautista de Toledo, Becerra se instala en Madrid en 1562, donde permanece hasta su muerte en 1568 ocupado en la ornamentación al fresco de los sitios reales con una actividad frenética al frente de un considerable número de oficiales, como un jefe de taller que proporcionaba directrices muy precisas para desempeñar el trabajo.

Ha sido este modo de trabajar en los diferentes proyectos pictóricos que afronta, el que conduce a reflexionar sobre su papel como escultor, en las escasas pero magníficas obras que de él conocemos de manera fehaciente. Todo parece apuntar a que su labor fue la misma, especialmente cuando se había formado con el trabajo pictórico, primero en Baeza en el taller paterno ${ }^{3} \mathrm{y}$ después en Italia con los grandes fresquistas. Becerra dirigió a un equipo de notables profesionales que le acompañaron a lo largo de toda su vida, proporcionándoles trazas y modelos verdaderamente innovadores, donde nada más era necesario aplicar una gran habilidad técnica.

Sorprendentemente sólo el retablo de Astorga y el perdido de las Descalzas Reales de Madrid, del que conocemos la traza, fueron las obras de escultura que acometió. Es significativo que otras obras de talla contratadas al hilo de su estancia en Astorga fueran al final traspasadas a artistas de su entorno ${ }^{4}$, sin que tengamos otros ejemplos conocidos para poder constatar su presencia. Tanto en Astorga como en las Descalzas estuvo presente, y no de modo casual, Bartolomé Hernández, ensamblador y escultor de alta calidad que después de la muerte de Becerra se instalará de nuevo en Astorga, al lado de otros miembros de su equipo como su propio hermano Juan Becerra, Miguel de Ribas o Baltasar del Torneo entre otros muchos, formando un grupo compacto y multidisciplinar, ligado a través de relaciones familiares. Nuevos datos, como la documentación testamentaria de su viuda ${ }^{5}$, complemento al testamento del artista que diera a conocer Llaguno ${ }^{6}$, aportan detalles que permiten echar a andar esta hipótesis, por lo demás señalada muchas veces de un modo indirecto, que haría contemplar a Becerra como un espléndido tracista y no como un práctico de la escultura; como un magnífico diseñador que supo impregnar con su imaginación todas las formas artísticas del momento.

Desde que Ceán mencionara la fecha en la que se produce el testamento de Becerra y el escribano ante el que testó en Madrid, el 22 de enero de 1568, nadie hasta la ingente recopilación de Llaguno, reparó en el interés que podía aportar el texto, reproduciéndolo en el apéndice documental de su obra. La conservación de los papeles del escribano Diego Méndez, en el Archivo Histórico de Protocolos de Madrid, ha servido para obtener nueva documentación en la que no se había reparado, que nos acerca mucho más a la figura de Becerra y sus condicionantes.

3 Su padre Antón Becerra es un interesante pintor que desarrolla su trabajo en Jaén (Angulo Iñíguez, D.: «Pintores cordobeses del Renacimiento», $A E A, \mathrm{n}^{\mathrm{O}}$ 64, 1944, pp. 226-244). Como se puede ver en el esquema de relaciones que insertamos al final, la familia directa de Gaspar está formada por pintores.

${ }^{4}$ Un ejemplo puede ser el retablo de Casayo (Orense),finalmente realizado por Pedro de Arbulo, otro de sus grandes discípulos en Astorga y por el pintor Pedro de Bilbao. González García, M. A.: «Pedro de Arbulo Marguvete y Gaspar Becerra» en Jornadas españolas sobre el Renacimiento, Principe de Viana, anejo 10, 1991, pp. 211-215.

5 En el apéndice documental insertamos fragmentos de la trascripción de los documentos localizados en el Archivo Histórico de Protocolos de Madrid (AHPM) y en el Archivo Histórico Provincial de Valladolid (AHPV), sobre los que se ha elaborado el presente artículo. Agradecemos en Valladolid, las atenciones de Ángel Laso, director del Archivo, y del investigador Miguel Ángel de Benito, tan útiles para este trabajo. A lo largo del texto se citan otros documentos de este conjunto que no hemos considerado necesario transcribir.

6 Llaguno y Amirola, E.: Noticias de los arquitectos y arquitectura de España desde su restauración (Ed. fac.), T. II., Madrid, 1977, pp. 261-263. La muerte de Becerra al día siguiente de dictar su testamento en Madrid, el 23 de enero de 1568, es un hecho demostrado después de las aclaraciónes de Veronique Gerard: De castillo a palacio. El alcázar de Madrid en el siglo XVI, Bilbao, 1984, pp. 89-96. 
La revisión de las escrituras de Diego Méndez, aporta en primer lugar la súplica al rey de protección para su esposa y para sus oficiales en el arte del estuco, Miguel de Ribas, Miguel Martínez y Baltasar del Torneo, que tanto Ceán como Llaguno mencionaron de pasada sin apuntar su procedencia, y que consideramos importante transcribir aquí ${ }^{7}$. En el documento Becerra, además de las alabanzas a sus colaboradores indica que Ribas ha recibido instrucciones precisas para dirigir el taller de estuco, lo que supone una novedad en la consideración de este escultor y en su estatus dentro del equipo ${ }^{8}$.

Becerra ordena la redacción del documento, imposibilitado para firmarlo a causa de la gravedad de su enfermedad, para intentar asegurar la continuidad de sus colaboradores en las obras reales. Sabemos con certeza que tanto Ribas como Torneo están acompañándole en el retablo de Astorga, y habrá que pensar, según iremos viendo en el desarrollo de este trabajo, que su origen, formación y adscripción al taller de Becerra ha tenido que hacerse en Valladolid, donde se instala a su regreso de Roma y donde contrata sus primeras obras en España. La categoría de los talleres vallisoletanos en el trabajo de la madera, tuvo que ser el principal apoyo de Becerra para introducirse en un género en el que no se había formado, que sin embargo era reclamado por la clientela hispana. El ejemplo más claro de esta transformación es la trayectoria de Alonso Berruguete, convertido plenamente al trabajo del género escultórico a pesar de su inicial y brillante formación pictórica.

Al lado de esta súplica dirigida a Felipe II en favor de sus más directos colaboradores, el mismo día 22 de enero se registra un codicilo donde aclara algunas de sus mandas, relativas a asegurar el patronazgo de su mujer sobre la capilla de enterramiento en la iglesia conventual de la Victoria de Madrid y al acompañamiento que ha de recibir su cuerpo por parte de la cofradía de la Soledad. Junto a esto se indican algunos detalles de tipo económico, como el pago a Francisca del Torneo, sobrina de Paula Velázquez y servidora del matrimonio.

El fallecimiento de Becerra al día siguiente de dictar estos documentos hizó ponerse en marcha los mecanismos de su herencia. Ante Diego Méndez se registra el 27 de febrero un poder otorgado por los frailes de la Victoria y Paula Velázquez, como herederos del difunto, a fray Pedro de Valdés, para cobrar en Baeza de Leonor de Padilla, madre del pintor, un previlegio de su magestad de treynta mil maravedis de juro en cada un año situado en la villa de belmez que es en el andaluzia. El juro había sido vendido a los mínimos de la Victoria por Becerra y su esposa a cambio de la capilla de enterramiento y de la atención a sus memorias y aniversarios. Asimismo fray Pedro de Valdés deberá cobrar unos censos asignados a la dicha capilla que el propio Becerra tenía en Andalucía.

\section{El testamento y los codicilos de Paula Velázquez}

\section{Modelos y dibujos. Trazas y monteas}

En el mismo año del fallecimiento de Becerra, en 1568, Paula Velázquez dictará su propio testamento ante Diego Méndez. Al documento siguen dos codicilos, uno en agosto y otro en diciembre, en los que se puntualizan detalles referentes a algunas de las mandas o se

\footnotetext{
7 Ver el apéndice documental.

8 Sobre Ribas nos indica Ceán su relación con Becerra y su vinculación a las obras reales hasta su fallecimiento en 1581, Op. cit., T. IV, p. 184. Martín González dio a conocer una carta por la que reclamaba el cobro de su salario, fallecido Becerra, en la que afirmaba que se había trasladado de Astorga a Madrid para trabajar en los sitios reales, «El Palacio de El Pardo en el siglo XVI», BSAA, T. 36, 1970, pp. 19-20, 37-38.
} 
aportan nuevas consideraciones. La relación de la viuda de Becerra con Tordesillas, donde residía su familia, originó que en 1570 los frailes de la Victoria, como herederos de sus bienes, se vieran obligados a hacer un traslado de parte de esta documentación a Tordesillas, con el objetivo de reclamar parte de su herencia y de resolver cuentas pendientes con los familiares de la difunta, ocasionados en vida de Becerra. La documentación se nos ha presentado de este modo de manera doble y con datos complementarios que enriquecen la información ${ }^{9}$.

$\mathrm{Al}$ igual que sucede en la práctica totalidad de su documentación particular y coetánea, de la que tendríamos que excluir los comentarios de los tratadistas, ajenos a este tipo de matizaciones técnicas, Becerra siempre es denominado exclusivamente como pintor del rey. En ningún caso se le menciona como escultor, salvo en el contrato del retablo de Astorga, donde es citado como pintor y escultor, al enfrentarse con una obra plenamente escultórica. Es sin embargo un hecho que se estaba encargando también de esta actividad en Madrid, al servicio de la princesa Juana de Portugal, en el conjunto de los retablos de las Descalzas Reales.

Son los datos que se desprenden de su intervención en esta obra, a través de los documentos testamentarios de Paula Velázquez, los que permiten afianzar la idea de encontrarnos ante un pintor que rige un enorme taller no sólo de pintores, sino también de escultores y ensambladores de gran pericia, que siguen al pie de la letra, en lo tocante al diseño y al tratamiento formal de la escultura y de la retablística, las indicaciones de Becerra.

En el segundo codicilo de Paula Velázquez, se reclama el pago de un machón de pino para los retablos colaterales de las Descalzas que había tomado el secretario de la princesa, a quien también se pide que pague el gasto del dorado de las puertas del retablo, que ha de ser el mayor, al aparecer citado en singular. Lo que aún se debía, además, era el importe de traças y monteas, que Becerra había realizado para ambos retablos colaterales. El uso del término montea, habitual en los despieces de cantería, y entendido como cartones, dibujos a tamaño natural de la obra a realizar, está indicando que Becerra trabajó en este caso de igual modo que en las pinturas de los sitios reales ${ }^{10}$, proporcionando bocetos muy terminados que su taller se encarga de materializar definitivamente.

El hermano de Becerra, Juan, otro de sus colaboradores en las obras madrileñas formando parte de ese taller que capitaneó, aparece en el testamento adeudándole unos dineros que tenía por gastar, con toda seguridad invertidos en la obra de las Descalzas donde Juan Becerra debía ser la sombra del maestro. El segundo codicilo va a pedir que se aclaren las deudas existentes entre ambos hermanos en virtud de una clausula existente en el testamento de Gaspar Becerra ${ }^{11}$, añadiendo que se solucionen además las cuentas con el mercader Juan Llorente, quizás uno de los encargados del suministro de materiales para las obras.

La presencia de Bartolomé Hernández, ensamblador andante en corte como testigo en el testamento de Paula Velázquez, es otro testimonio de su estancia en Madrid implicado en las obras de escultura del retablo de las Descalzas, en el que cumplirá la misión con la que se le nombra en el documento, como sucedió en el retablo de Astorga. La estancia de Hernández en Madrid, que posteriormente se ligará por lazos matrimoniales en Tordesillas con una prima de

9 En el apéndice se transcribe la mayor parte de dos de estos documentos, que aportan ciertas novedades, trasladados ante el escribano de Tordesillas en 1570.

${ }_{10}$ Este sistema de trabajo está perfectamente explicado en el trabajo citado de Gerard.

11 En su testamento, Becerra indicaba que fuera su hermano Juan quien llevara a cabo el dorado y estofado de los retablos de las Descalzas. Llaguno: Op. cit. Martín González documenta el trabajo de Juan Becerra pintando los cajones de la Armería del Alcázar, Op.cit., p. 330. Su hija María contraerá matrimonio con el escultor Esteban Jordán en segundas nupcias y otorga testamento en 1567 (Martí y Monsó, J.: Estudios histórico artísticos relativos principalmente a Valladolid, Valladolid, 1900, p. 548). 
Paula Velázquez, quedaba clara en las declaraciones de los testigos en el pleito por el retablo de los Alderete de Tordesillas y pone de manifiesto la destacada figura de este artista en la obra escultórica dirigida por Becerra ${ }^{12}$.

Es importante el dato que el segundo codicilo proporciona, relativo al pago reclamado al pintor vallisoletano Jerónimo Vázquez. El testamento de Becerra indicaba tan solo que el pintor tenía un arca con modelos suyos que debían reclamarse. Paula Velázquez aclara más la deuda especificando que se trata de todos los modelos que su marido truxo de ytalia. Que esta valiosa colección se encontrara en manos de tan mediocre artista ${ }^{13}$, presente otras veces en el entorno de Becerra, es algo incomprensible, a no ser que estemos ante otro rasgo de puro mercantilismo artístico de amplias consecuencias, o que únicamente conozcamos la obra pictórica de Vázquez antes de recibir el aprendizaje de estas novedades formales. El hecho demuestra que Becerra vino de Italia con un notable bagaje material, sustento indudable de toda una renovación de formas, pronto extendidas entre los medios artísticos.

El funcionamiento de ese taller a través de trazas previas, donde realmente se encontraba la innovación en los esquemas del retablo, se observa también en la propia situación del retablo mayor de Santa María de Mediavilla en Medina de Rioseco. Paula Velázquez declara que la traza realizada por su marido, está en su poder y ofrece su compra, si es que interesa a la iglesia de Rioseco, a donde se llevaría en mano por alguno de sus parientes. La traza fue posteriormente aceptada, según se observa por la documentación aportada por García Chico ${ }^{14}$, y seguida por Juni, Jordán y el resto de maestros que participaron en la obra del retablo.

Tras la muerte de Paula Velázquez, entre diciembre de 1568 y febrero de 1569, la comunidad madrileña de la Victoria otorga un poder a sus hermanos de orden en Valladolid para recibir los bienes que se le adeudaban de la herencia, volviendo a insistir de nuevo en el bagaje de los bienes artísticos de Becerra centrados en temas pictóricos. El poder, de 3 de febrero de $1569^{15}$, ha de servir para que puedan reclamar pinturas, dibujos de las arcas de papeles y traças y otros cualesquier bienes... con el fin de enviarlos a Madrid, además del dinero que por distintas circunstancias se le adeudara.

De nuevo son los modelos pintados lo que se recuerda expresamente en el documento, y los que en definitiva tendrían valor para sus herederos, sin señalar de forma específica otros bienes relacionados directamente con lo escultórico, como una mera actividad circunstancial emprendida por el pintor. El documento que dio a conocer Iñiguez Almech, por el que Felipe II reclamaba los enseres artísticos que quedaban en el aposento de Becerra a su muerte, es más que elocuente. Bocetos, dibujos y proyectos, hasta para el capillo de un ornamento ecle-

12 En el testamento de Becerra figura como testigo, además de señalar que el maestro le debía 35 ducados menos cinco reales que le había prestado. Ibidem, pp. 432 y ss. transcribe datos del pleito por el retablo de la capilla de los Alderete, donde uno de los testigos afirma que Hernández ha demostrado su maestría en los retablos de Astorga y de las Descalzas de Madrid. Martín González juzga exagerada la afirmación, considerándola una pura maniobra jurídica. Sobre el escultor puede verse el artículo de González García, M. A.: «El retablo mayor de Bercianos de Vidriales» en Astorica, $\mathrm{n}^{\mathrm{o}}$ 1, pp. 99-119, León, 1983.

13 Es necesario diferenciar la obra de Vázquez, hijo del prolífico Antonio Vázquez, que debió de detentar un taller trabajando en compañía, con mucha presencia pero con escasos resultados. Su obra documentada y firmada en Santoyo junto al palentino Antón Calvo, al final de su vida, puede ser fundamental para valorar la evolución de su estilo. Zalama, M. A.: Santoyo. Iglesia de San Juan Bautista, Palencia, 1992.

${ }_{14}$ García Chico, E.: Documentos para el estudio del arte en Castilla. Escultores, Valladolid, 1941, pp. 43 y ss.

15 AHPM, Diego Méndez, nº 388, 1569, s/f. AHPV, Francisco del Torneo, no 4520, 1570, fol. 494-495. En el mismo poder se pide que se trasladen a Madrid las posesiones de Becerra en Valladolid, indicando que aún se le debían 150 ducados en Astorga y que el pintor y su esposa eran propietarios de un juro en Tordesillas. 
siástico, son apuntados por el rey por ser necesarios para quando se ayan de proseguir, pensando en que fueran otros pintores quienes aprovecharan las indicaciones del maestro ${ }^{16}$.

\section{La ornamentación de la capilla de la Cruz, en la Victoria de Madrid}

El 1 de septiembre de 1567 se registran las capitulaciones entre Gaspar Becerra, criado de su majestad sin que se aclare su profesión, y su esposa Paula Velázquez, con el convento y frailes de Nuestra Señora de la Victoria de Madrid, sobre la adquisición de una capilla en la iglesia de dicho convento, cuya venta se formaliza el día 10 del mismo mes ${ }^{17}$. La compra de este espacio funerario manifiesta la consideración social del artista y su poder adquisitivo. La documentación relativa a esta transacción es parca en datos relativos a la ornamentación del ámbito. Se especifica de qué capilla se trata de las que estan en la yglesia del dicho monasterio que es la questa a la mano derecha del evangelio la questa mas avajo de la capilla de nuestra señora de la vitoria que alinda con la puerta de enmedio de la yglesia. La venta, en 30.000 maravedis de juro, permite que la labreis con la labor y hornato que quisieredes y por vien tubieredes a vuestra costa y para que sea enterramiento de vos y vuestros herederos y subzesores e de quien quisieredes. La capilla se llama y se ha de llamar de la cruz ques quando Cristo salio de jerusalem con la cruz a questas. Ningún detalle más señala peculiaridad alguna acerca del recinto, donde se habrán de celebrar un abundante número de sufragios por las almas de los patronos incluida Leonor de Padilla, madre del artista. Las fechas de la celebración de misas son considerables y abarcan la práctica totalidad de las fiestas litúrgicas.

El resto de la documentación de Paula Velázquez sirve para ofrecer más datos referentes a este tema. El testamento añade que la capilla, en obras al igual que el resto del edificio, debe cerrarse con su correspondiente reja, sin que se faciliten más detalles al respecto. Se pintará de blanco y se construirá una bóveda honesta como lugar de enterramiento. En cuanto a la decoración señala que se debe hacer, tal y como tenía acordado con su marido, un retablo representando la salida de Cristo de Jerusalén camino del Calvario, de pintura. Al otro extremo de la capilla, la representación iconográfica elegida es la de San Juan Bautista, tal vez porque a la muerte de Becerra el patronazgo habría de ser compartido por su viuda y su hermano Juan.

El codicilo redactado el 13 de diciembre de 1568, aclara que todavía está por realizar lo encomendado. El trabajo debe hacerse como estaba programado por Becerra y su esposa, a las órdenes del padre fray Juan de Valdés, de la orden de mínimos, confesor y testamentario de Paula Velázquez, a quien ésta indica que era mucho lo que le debía su marido ${ }^{18}$.

16 Íñiguez Almech, F.: Casas reales y jardines de Felipe II, Cuadernos de trabajo de la Escuela Española de Historia y Arqueología, CSIC, Madrid, 1952, p. 205 (Archivo del Inst. Valencia de Don Juan, Envío 61, no 160, Febrero, 1568 «un dibujo que hizo del martirio de San Lorenço para el capillo de una capa, una tracilla del modo que podrian ser las Estaciones del Escorial, otra de las ventanas que se abrian de pintar en el terrado de ay, debaxo de las ventanillas que ya se pintaron en alto. No se si ay alguno de la sala grande y de la quadra donde yo me visto ay, y estan las quatro pinturas grandes del Bosque de Segovia, y quiza deve de aver otras cosas que avia hecho para my, y tambien la traça de lo que abia de pintar en esa estufa...»).

17 AHPM, Diego Méndez, nº 387, 1567, s/f.

18 La figura de este religioso puede ser la clave para explicar la relación de Becerra con la orden de San Francisco de Paula ya en la iglesia italiana de la Trinita dei Monti, y quizá con la propia corte a través de la devoción de la reina Isabel de Valois por esta orden. En este aspecto no podemos olvidar el encargo de la Virgen de la Soledad a Becerra y la leyenda de su mítica talla, prolijamente relatada por Tormo utilizando fuentes antiguas. 
La pintura se especifica que ha de ser ejecutada por micer Romulo, que no puede ser otro que el pintor Romulo Cincinnato, llegado de Italia en 1567 para trabajar con Becerra, como expresión del gusto que se imponía en la corte y vinculado a las obras áulicas de Felipe II hasta su muerte ${ }^{19}$. En la descripción que hace Ponz de la capilla de enterramiento de Becerra se menciona la pintura del Cristo camino del Calvario en el retablo que se atribuye al artista ${ }^{20}$. La pintura, que por tanto se realizaría según expresaba en su voluntades Paula Velázquez, sería obra de Cincinnato, a quien Becerra considerara el más digno para perpetuar de esta manera su memoria.

También Paula Velázquez deja para el ornato de la capilla, frontales de seda y un cáliz de plata con su patena sobredorada que pesa 30 ducados. Habrá que pensar en la hechura de este cáliz tal vez por el platero que figura en el testamento de Becerra, Francisco de Soto, de familia de orfebres vallisoletanos pero asentado en Astorga. Las obras de la catedral generaron el movimiento de un buen número de artistas, entre los que hay que incluir a Soto junto a otros interesantes orfebres del momento como Sebastián de Encalada. En Astorga estará residiendo largo tiempo, coincidiendo con la estancia de Becerra en la ciudad ${ }^{21}$.

\section{Deudas con las obras en los sitios reales y menciones a otros artistas}

El testamento menciona en primer lugar la deuda de 200 ducados con Becerra, producto de ciertos salarios corridos, que habrían de ser pagaderos por Luis Hurtado, el veedor de las obras del Pardo, que con tanta frecuencia figura en la documentación del momento. El dinero se dice que está en manos del pagador Santoyo, a quien se hará la reclamación pertinente. Naturalmente la noticia está haciendo referencia a las obras llevadas a cabo tanto en el Alcázar como en el Pardo, donde Becerra estaba al frente de su equipo.

Además de los citados Bartolomé Hernández, Juan Becerra, Jerónimo Vázquez y Rómulo Cincinnato, otros artistas aparecen firmando como testigos en los documentos de la viuda de Becerra o relacionados con diferentes asuntos. Diego de Urbina, pintor y vecino de la villa de Madrid, que tanto tendrá que ver con la pintura escurialense ${ }^{22}$, es uno de ellos, vinculado de este modo más directamente a las influencias de Becerra.

19 Cincinnato trabajará en origen con el Bergamasco. Posteriormente pasa a engrosar el número de pintores italianos que trabajan en El Escorial. Zezza, A.: «Romolo Cincinnato: los frescos del coro y del claustro de los Evangelistas», pp. 121-124, en Los frescos italianos de El Escorial, Madrid, 1994, pp. M. di Giampaolo (coord.).

${ }_{20}$ Ponz, A.: Viaje de España (1776), Madrid, 1947, pp. 490, 491. Al describir la iglesia de la Victoria señala la existencia de un cuadro con una Sagrada Familia y Santa Catalina que atribuye a Becerra. Del mismo artista dice que es el Señor con la Cruz a cuestas en la capilla de la Encarnación al lado de la Epístola. El dato es acompañado de una nota en la que menciona que la capilla, antes denominada de la Cruz fue el lugar de enterramiento de Becerra, aportando diversos detalles biográficos del artista extraídos de Palomino y del propio testamento del pintor. Desconocemos el actual paradero de esta pintura, después de la Desamortización.

21 La estancia de Francisco de Soto se documenta en Astorga no sólo a través del testamento de Becerra. Martí y Monsó, localiza un contrato de aprendizaje con él en Valladolid, en 1559, siendo vecino de Astorga, Menudencias biográfico-artísticas, BSCE, T. I, 1903-4, p. 254. En Astorga aparece como fiador de Becerra en el contrato, finalmente fallido, para policromar el retablo de Dehesas del Bierzo en 1562. Voces Jolías, J. Ma.: Arte religioso en el Bierzo en el siglo XVI, Ponferrada, 1987, pp. 460-462. El testamento de Becerra indica que el platero le adeudaba 100 ducados.

${ }^{22}$ Antonio Sáenz, T. de: Pintura española del último tercio del siglo XVI en Madrid: Juan Fernández de Navarrete, Luis de Carvajal y Diego de Urbina (tesis doctoral sin publicar), Ed. Univ. Complutense de Madrid, 1987. Hermano de Urbina es Francisco de Ampuero, otro de los testigos del testamento de Paula Velázquez. 
El funcionamiento del taller a través de vínculos familiares que se iban entretejiendo entre los artistas, tiene un claro ejemplo en el caso de Becerra. Además de su hermano, el primero de los codicilos de Paula Velázquez proporciona el nombre de un sobrino de su marido, Francisco Becerra, que residía en su casa y que ganaba 5 reales diarios. Hemos de suponer que se trata del pintor Francisco Becerra, documentado trabajando en la catedral de Toledo por Zarco del Valle en dos ocasiones, en los años 1569 y $1579^{23}$. En el claustro de la catedral primada se registra el encargo a Gaspar Becerra de la pintura al fresco de uno de sus lunetos en $1563^{24}$, donde con seguridad se inicia esa relación con la fábrica.

Otro familiar cercano es Baltasar del Torneo, testigo del codicilo final de su prima Paula Velázquez, y uno de los miembros más representativos del taller de Becerra, a quien ya acompañó en Astorga. Torneo, natural de Tordesillas, entra al servicio real documentando Gerard su presencia en Madrid y también será uno de los testigos que firman en el codicilo del arquitecto Juan Bautista de Toledo ${ }^{25}$, avalando esa relación existente con Becerra originada en su estancia romana. Lo mismo que sucedió con otros de sus colaboradores, permanecerá en Madrid hasta su muerte, al servicio de la casa real ${ }^{26}$.

El último codicilo recuerda una deuda de 70 reales que debía a su marido Manuel Álvarez, aclarando su oficio y nacionalidad como entallador portugués, que figura en las relaciones de artistas que están trabajando en los sitios reales el tiempo que Becerra ${ }^{27}$, y en otro tipo de documentación palaciega. Nada permite afirmar que este entallador luso tenga algo que ver con el artista homónimo, que desarrolla su labor en Palencia dentro de una destacada familia de escultores ${ }^{28}$.

Gaspar de Hoyos, el policromador del retablo de Astorga junto a Gaspar de Palencia a partir de 1569 , otro de los pintores que estaba en el taller de Becerra en Madrid ${ }^{29}$, aparece reclamando una cantidad a Paula Velázquez, por lo que ella manifiesta que nada se le debe de la demanda que aducía. En Madrid seguirá el pintor al servicio de la corte hasta que sea contratado por el Cabildo astorgano para llevar a cabo la policromía del retablo, en cuyo empeño finalmente fallece.

\section{Datos familiares}

Otras aportaciones presentan los documentos testamentarios de Paula Velázquez, que pueden resultar de interés a la hora de conocer la vida privada de la viuda đel artista, cuya

23 Zarco del Valle, M. R.: Datos documentales para la historia del arte español, II. Documentos de la catedral de Toledo, Madrid, 1916, pp. 193 y 209.

${ }_{24}$ Ibidem, pp. 138-139, 141. Se conserva el dibujo preparatorio reproducido en Angulo Íñiguez, D. y Pérez Sánchez, A. E.: A corpus of Spanish drawings, 1400-1600, T. 1, Londres, 1975, p. 22 y IX, 27.

${ }_{25}$ Llaguno y Amirola: Op. cit., T. II, p. 242.

26 Baltasar del Torneo aparece siempre mencionado al lado de Becerra. Gerard indica el momento de su incorporación a las obras reales. Muere hacia 1579 fuera de Tordesillas, seguramente en Madrid. En 1583 se resuelve en su villa natal la curaduría de su hijo pequeño de cuatro años, Baltasar Ugarte del Torneo, fruto de su matrimonio con Ana de Ugarte, también de Tordesillas y difunta, que había quedado embarazada a la muerte de su marido. El curador es el hermano de Baltasar y también criado de Becerra, Ventura del Torneo y como uno de los fiadores figura Bartolomé Hernández, en ese momento en Tordesillas (AHPV, Francisco del Torneo, ${ }^{\circ s} 4533$, 1583 , fols. 526 y ss.).

27 Manuel Álvarez arquitecto y escultor, aparece citado en las obras del Alcázar el 9 de mayo de 1568, estimando unas chimeneas. El dato figura en Gerard, Op. cit., p. 167. La deuda era ya mencionada en el testamento de Becerra.

${ }_{28}$ Parrado del Olmo, J. Ma․: Los escultores seguidores de Berruguete en Palencia, Valladolid, 1981.

29 La noticia fue dada a conocer por Martín González en «El Alcázar de Madrid en el siglo XVI (nuevos datos)», $A E A, \mathrm{n}^{\mathrm{0}} 137,1962$, p. 17. 
muerte acontece en breve espacio de tiempo tras la de su marido. La voluntad de enterrarse con el hábito de San Francisco de Paula, compartida por su marido, no es más que la expresión devota por esta orden, heredera de sus bienes, y con una gran presencia en la vida del matrimonio. La petición del acompañamiento por parte de la cofradía de la Soledad, a la que pertenecía, es lógica si recordamos que fue Becerra el encargado de realizar esta imagen vestidera que tanta trascendencia había de tener entre las devociones marianas españolas,y que también se pedía en el codicilo del propio Becerra.

Al lado de las tradicionales mandas piadosas en misas por su alma y en limosnas a diferentes instituciones religiosas y benéficas de Madrid, Paula Velázquez determina la sucesión en el patronazgo de la capilla asignada a uno de sus testamentarios, el doctor Céspedes, médico del rey, y su mujer Ana de Espinosa. La circunstancia de que Céspedes fuera originario de Tordesillas ${ }^{30}$ y quizás pariente de la propia viuda, explica el hecho. Naturalmente no olvida en el testamento a su familia directa, a sus sobrinas, que posiblemente vivirían con ella, y a sus primas las hijas de su tío Pedro del Torneo, a las que deja una cantidad destinada a servirles de dote en su matrimonio ${ }^{31}$. Ningún problema parece surgir a la muerte del artista entre su esposa y su madre, Leonor de Padilla, heredera de Becerra al no existir hijos de su matrimonio, según se indica en su testamento. En los protocolos de Tordesillas se añade el concierto entre ambas, realizado en Madrid el 13 de octubre de $1568{ }^{32}$.

Los documentos recuerdan también deudas con el pañero Alonso Pardo, relativas a ropas de duelo y otros asuntos domésticos pendientes, como la breve descripción de alguna de su joyas o la venta de Dominga su esclava negra ${ }^{33}$. Las deudas que aún estaban pendientes en Astorga hemos de suponer que hacen referencia al retablo, aunque resulte una curiosidad insistente la cantidad que le está debiendo la marquesa de Astorga, ya anotada en el testamento del artista, referida a algún trabajo realizado por Becerra del que no tenemos más noticias.

\section{Las cuentas del bachiller Pedro del Torneo}

Entre los documentos generados por la herencia de la viuda de Becerra, y lo que en fin permitió su traslado a la escribanía de Francisco del Torneo, se encuentran las cuentas que presenta el bachiller Pedro del Torneo al convento de la Victoria de Madrid. Pedro del Torneo ha sido el representante legal de Becerra en Tordesillas, el encargado de su hacienda en el entorno de la villa del Duero, obligado ahora a clarificar su situación económica ante los herederos legales, en lo referido a gastos e ingresos del matrimonio que él había administrado.

Tenemos noticia de la figura de este clérigo, primo de Paula Velázquez y personaje sin duda de peso en la sociedad de su tiempo. Sabemos que era beneficiado de la iglesia de Velilla y capellán de la fundación que Rodrigo de Burgos dejara instituida en la parroquia de Berceruelo, en su capilla de la Visitación. Su nombre se repite con frecuencia en la docu-

$30 \quad$ Fernández Torres, E.: Historia de Tordesillas (Ed. Facsímil), Valladolid, 1982, pp. 224-227.

${ }^{31}$ AHPV, Francisco del Torneo, $\mathrm{n}^{\mathrm{os}} 4521,1571$, fols. 1374 y ss. En este documento se registra una carta de pago del monasterio de la Victoria de Madrid en favor de Pedro del Torneo, con la entrega de 30 ducados en cumplimiento de las mandas de Paula Velázquez, para la dote de su hija Francisca. Pedro del Torneo es también el padre de el escultor Baltasar del Torneo y de Luisa del Torneo, quien se casará con Bartolomé Hernández.

${ }^{32}$ AHPV, Francisco del Torneo, $\mathrm{n}^{\text {os }} 4520,1570$, fols. 502-504.

33 AHPM, Diego Méndez, no 388, 1569, fol. LV-LVI. El documento registra la venta efectuada el 3 de febrero de 1569 de una esclava negra llamada Dominga y su hija de meses, Lucrecia, que fueron propiedad de Paula Velázquez y ahora habían sido heredadas por el convento de la Victoria de Madrid. Ambas son vendidas por 124 ducados a Catalina de Valdés, amiga de Paula Velázquez y a quien ella misma indicó que se vendieran. 
mentación de los protocolos notariales de Tordesillas, con una ingente actividad económica tanto propia como relativa a la administración de esa rica capellanía cuyas rentas disfrutaba.

Parrado ha documentado la fecha de su muerte el 23 de septiembre de 1591 y analiza algunos de los datos existentes en su testamento, entre otros la posesión de objetos de orfebrería y de lienzos con temas devocionales ${ }^{34}$. Posteriormente hemos localizado el reparto de sus bienes entre sus familiares ${ }^{35}$, intentando recabar más datos sobre su personalidad, con la idea de poder encontrar de un modo indirecto más noticias relacionadas con Becerra. Correspondiente a su dignidad y a su poder económico, sabemos que su enterramiento tuvo lugar en la capilla que adquirió en la iglesia de Santa María en $1576{ }^{36}$, firmando el contrato de obra con el maestro transmerano Diego de Hano al año siguiente, según nos diera ya a conocer García Chico ${ }^{37}$, encargando la hechura de una reja a los maestros vallisoletanos Juan de Pedregal y Alvaro de la Peña ${ }^{38}$.

Las cuentas que presentó en el año 1568 sobre su capellanía de Berceruelo (Valladolid), sirvieron en tiempos para documentar una obra perdida de Becerra ${ }^{39}$, el retablo de la Visitación que encargara su fundador Rodrigo de Burgos. Una nueva lectura de las mismas sirve para reordenar la actividad del artista. Torneo afirma que en la fecha citada había terminado de pagar lo que se le adeudaba a Becerra, al que sin embargo el propio Rodrigo de Burgos, en vida, ya había satisfecho los primeros pagos. En marzo de 1558 muere el fundador de la capellanía ${ }^{40}$, por lo que hemos de pensar que el trabajo de Becerra se realizó en esos momentos, diez años antes de lo que se venía pensando. La obra hubo de ejecutarse recién llegado Becerra de Italia e instalado en Valladolid, cerca de su familia política en Tordesillas, donde tuvo que proveerse de oficiales dignos de seguir sus indicaciones. Será su influencia la que le permitirá conseguir el contrato para la que tuvo que ser su primera obra en nuestro país, justo en el momento en que se compromete a realizar el retablo mayor de la catedral de Astorga siendo vecino de Valladolid.

Estas gestiones, que tuvieron que tener presente a Pedro del Torneo, han de estar en el inicio de su actividad como el hombre de confianza de Becerra, especialmente cuando a partir de 1562 los encargos reales ocupen casi todo su tiempo. Las cuentas presentadas por el bachiller al convento de la Victoria en $1570^{41}$, muerta ya Paula Velázquez, son un fiel testimonio de su papel como agente en los asuntos del pintor en su más inmediato entorno geográfico, al tiempo que aporta nuevos datos sobre la condición social y la vida diaria del artista.

La sucesión de gastos que va relatando Pedro del Torneo plantea el problema de la falta de datación concreta para cada uno de ellos, que ayudaría todavía más a centrar con exactitud los acontecimientos. Los diferentes asuntos debemos sin embargo localizarlos entre 1562 y 1568, desde el traslado de Becerra y su casa de Astorga a la corte hasta el momento de su muerte, según se desprende de los detalles descriptivos.

34 Parrado del Olmo, J. Mㄹ.: «Patronos y obras de arte en Santa María de Tordesillas», BSAA, 56, 1990, pp. 525-527.

35 AHPV, Francisco de Palencia, ${ }^{\text {os }} 4477,1593$, fols. 427 y ss.

${ }^{36}$ AHPV, Francisco del Torneo, $\mathrm{n}^{\text {os }} 4526,1576$, fols. 648 y ss. compra de un arco en la iglesia de Santa María.

37 García Chico, E.: Documentos para el estudio del arte en Castilla. Arquitectos. Valladolid, 1940, p. 57.

38 Parrado del Olmo, J. Mㄹ.: «Patronos...», pp. 525-527.

39 García Chico, E.: Op. cit., pp. 67-68. Martín González: «Precisiones...», pp. 338-339.

40 En el AHPV, Fernando del Torneo, $\mathrm{n}^{\mathrm{os}}$ 4424, 1558, fol. 551, se registra un inventario de los bienes de Rodrigo de Burgos, que ha fallecido el 26 de marzo de 1558. Su testamentario es el bachiller Torneo.

${ }^{41}$ El 16 de abril de 1570 el convento de la Victoria de Madrid otorga un poder a fray Jerónimo de Santo Domingo y a fray Juan Martínez, para que vayan a Tordesillas a pedir cuentas al bachiller Torneo, en lo referente a la herencia de Becerra y a la cobranza de los beneficios reportados por el juro que éste tenía en la villa (AHPM, Diego Méndez, $n^{\text {os }} 389,1570$, s.f.). Las cuentas se transcriben en parte en el apéndice documental. 
Por un lado encontramos referencias a temas domésticos, relacionados con la economía familiar, con la compra de censos administrados por el propio bachiller en Medina del Campo y Peñaranda, a donde viaja con cierta asiduidad Pedro del Torneo con objeto de cobrar los beneficios que le reportaban a Becerra. El mismo Torneo se encarga de la compra y hechura en Valladolid de un frontal de altar, que Becerra y su esposa donan generosamente a Santa María de Tordesillas. En este capítulo se encuentra además el cobro de obligaciones y el envío de dineros de Becerra al bachiller con el objeto de hacer frente a los gastos ocasionados por diferentes temas. Torneo se encarga de representar a Becerra en un pleito que mantenía con el canónigo Urones, de la colegiata vallisoletana, detrás del cual tal vez pueda rastrearse una posible obra del artista, aunque no conozcamos ningún otro testimonio documental.

Las obras mencionadas con claridad en las cuentas son el retablo de la catedral de Astorga y el de Santa María de Medina de Rioseco. Respecto al primero se constata la visita de Torneo al cabildo y obispo de Astorga, Don Diego Sarmiento de Sotomayor, que se encontraba en Villafranca en el instante del encuentro, para tratar asuntos relativos al retablo, portando además dos cartas reales. Debemos suponer que la obra ya está terminada y que la visita está motivada por asuntos relativos al pago, cuando Becerra se encuentra trabajando en los reales sitios.

Viaja en persona a Rioseco, desde Madrid, para tratar temas referentes al retablo, recibiendo dineros del bachiller en Tordesillas. Similares motivos hacen que Ventura del Torneo, primo a su vez de Paula Velázquez, vaya a Rioseco, con seguridad desde Madrid, llevando cartas del artista relativas a la obra del retablo cuya traza, dejó terminada a su muerte en poder de su esposa.

También Torneo se encargó de la administración de los bienes, afrontando los gastos generados por el traslado de su casa de Astorga a Madrid. Las cuentas transmiten como Paula Velázquez recibió 200 reales cuando se encaminaba desde Astorga al sitio del Pardo para reunirse con su marido, lo mismo que sucede con su primo el mencionado escultor Baltasar del Torneo criado de Becerra ${ }^{42}$, que recibe del bachiller dinero necesario para trasladarse de Astorga a Madrid y unirse al equipo del maestro. Allí se ha de dirigir Ventura del Torneo desde Tordesillas, llamado por Paula Velázquez. La personalidad de este familiar político de Becerra, calcetero de oficio y sin aparente relación con el trabajo artístico, debe de nuevo vincularse a una función exclusivamente administrativa equiparable a la del mismo bachiller.

Los pagos efectuados por Torneo a tres artistas, que en esos instantes debían estar en Valladolid o en su entorno más inmediato, en nombre de Becerra, están hablando de unos contactos elocuentes a la hora de analizar el modo de trabajo. Gaspar de Hoyos, natural de Cuenca de Campos y perteneciente a una importante familia de policromadores, es uno de ellos. Hoyos está trabajando como pintor a las órdenes de Becerra en Madrid y, desde allí se trasladará a Astorga en 1569 para trabajar en la policromía del retablo catedralicio, donde fallece en 1573. Los motivos del pago habrá que buscarlos en alguna deuda que con él tuviera Becerra por las obras realizadas o quizás en algún trabajo comisionado por el propio artista para atender a su demanda.

Algo parecido tiene que suceder con los otros dos artistas mencionados, Antonio Vázquez y su hijo Jerónimo, cuya documentada relación con Becerra sigue sorprendiendo. Vimos como Jerónimo Vázquez tenía en su poder los modelos traidos de Italia por Becerra, aunque lo documentado de su pintura, al menos en su primera época o cuando realiza obras

42 González García, M. A.: «Pedro de Arbulo...», p. 213, documenta su estancia en Astorga como criado de Becerra. 
en compañia de Gaspar de Palencia ${ }^{43}$, no permitiera admitir que hubiera recibido del artista influencia alguna. Menos razones habría para justificar esa relación con su padre, el arcaizante aunque fecundo Antonio Vázquez, sino es a través de una relación mercantil alejada de cualquier concepto de escuela, como ya señalamos. Tendremos por tanto que pensar por el momento, en algún sistema de compañía que permita justificar este tipo de relaciones.

Una vez más los documentos no son suficientes para desentrañar la peculiaridad de las conexiones y el sistema de producción artística, a pesar de que puedan servir de pauta para acercarnos a conocer mejor los auténticos esquemas empleados. La actividad del taller y la figura de Becerra como un auténtico director de obras, también en lo que se refiere a la escultura, lo disponen en una dimensión más comprensible que debe valorarse.

\section{APÉNDICE DOCUMENTAL}

Súplica de Gaspar Becerra a Felipe II, en favor de sus oficiales y de su esposa, Madrid, 22 de enero de 1568 (AHPM, protocolos de Diego Méndez, 1568, $n^{\circ} 387$ ).

En la villa de Madrid a veinte y dos dias del mes de henero de mil e quinientos y sesenta y ocho años... parezio presente gaspar bezerra pintor de su magestad e dixo que el tiene hecho su testamento ante el presente escrivano el qual manda y quiere que se guarde y cumpla y que pide y suplica a su magestad el rey don felipe nuestro señor que por quanto el a servido a su magestad en las obras de los alcazares de esta villa y en la de el pardo destuco con toda boluntad y fidelidad posible y el a traido consigo en las dichas obras a miguel rribas official del dicho arte y a miguel martinez y a baltasar torneo y a otros officiales del dicho arte los quales con toda fidelidad y cuidado an servido a su magestad y son muy buenos officiales y espertos en el dicho arte y biendo que su magestad tiene neçesidad dellos para las dichas obras dixo que suplicava y suplico a su magestad aya y tenga por encomendado para su rreal serbiçio a los dichos miguel rribas y a miguel martinez y a baltasar torneo officiales del dicho officio de escultores porque son muy buenos officiales y servidores de su magestad para que su magestad les haga toda merced y el dicho miguel rribas a servido juntamente con baltasar torneo por zedulas de su magestad... que el dicho miguel rribas tiene del dicho gaspar bezerra para guiar y corregir a los officiales del dicho arte de estuco y suplico a su magestad les haga toda merced por haver serbido tan bien y merezerlo ellos por su bien saver y ansimysmo dixo que encomendava a su magestad a paula belazquez su mujer para que la favorezca y haga mercedes por quedar viuda y pobre y haver estado siempre en serbiçio de su magestad... e por la gravedad de su enfermedad e por no poder firmar obligo a un testigo lo firmase por el.

Testamento de Paula Velázquez, Madrid, 1 de junio de 1568, ante Diego Méndez (AHPM, protocolos de Diego Méndez, 1568, $n^{\circ}$ 387). (Traslado en el AHPV, protocolos de Francisco del Torneo, 1570, $n^{\circ} 4520$, Tordesillas, fols. 496-501).

\section{In dey nomine amen}

Sepan quantos esta carta de testamento e postrimera voluntad vieren como yo paula belazquez biuda muger que fui de gaspar vezzerra pintor que fue de su magestad difunto, enferma en la cama de enfermedad que nuestro señor fue servido de me dar paro en mi juiçio...

yten mando que quando la boluntad de dios nuestro señor fuere servido de me llebar desta presente bida mi cuerpo sea amortajado y bestido del abito del bienaventurado san francisco de paula y en un ataud y mi cuerpo sea enterrado en el monasterio de nuestra señora de la vitoria desta villa en mi capilla que es la capilla de la cruz adonde esta enterrado gaspar vezerra mi marido la qual dicha capilla compramos yo y el dicho mi marido del dicho monasterio... y baian a mi enterramiento todos los frailes... y seles de delimosna de mis bienes çien reales y se allen a mi enterramiento los ermanos de la confadria de la soledad de la madre de dios de las angustias desta villa donde yo soy cofadre conforme a los capitulos de la regla de la dicha cofadria

y tambien se allen a mi enterramyento los niños de la dotrina desta villa de madrid...

43 González García, M. A. y Arias Martínez, M.: «A propósito de Gaspar de Palencia» en el Boletín del Museo de Bellas Artes de Bilbao, 1993, pp. 21-47. 
y asimismo quiero que bengan a mi enterramiento los frailes de san francisco desta villa de madrid y me digan una vigilia y una misa cantada... e ansimismo vengan a mi enterramiento el cura de mi perrochia y seis clerigos con el...

yten mando que en el monasterio de nuestra señora de la bitoria desta villa de madrid y por los frailes del se digan las misas siguientes (comienza una larga serie de misas de acuerdo con la costumbre del momento)

yten mando que por quanto yo y el dicho gaspar vezerra mi marido que sea en gloria estando bivos y sanos mucho tiempo antes que muriese compramos la capilla que tenemos... y nos obligamos a la labrar y adornar decentemente y el dicho mi marido mando en su testamento que la dicha capilla se labre e yo ansimismo quiero y mando que lo que faltare a la hazienda del dicho mi marido para hedificar e adornar la dicha capilla se cumpla de mi hacienda con tanto que la capilla se aga con una boveda onesta y honrrosa y las paredes de la dicha capilla se blanqueen y se aga el rretablo que es lo prinzipal de la salida que jesucristo salio de hierusalen con la cruz a cuestas y en la pared del otro cabo un san juan bautista todo lo qual juntamente con la rreja para la puerta seya y declaro que hera voluntad del dicho gaspar vezerra mi marido que ansi se hiçiese...

yten mando que para el ornato del altar de la celebraçion de misas y otros dibinos ofiçios que se an de hazer en la dicha capilla se pongan dos frontales de seda a la boluntad de mi confesor e otro frontal... y un caliz de plata con su patena sobredorado que pese trinta ducados y para ello se haga un caxon y tenga la llave del el patron de la capilla.

yten mando a pedro del torneo mi tio çien ducados para casar a sus hijas y denselos luego

yten mando a mariquita torneo mi sobrina çien ducados y a clarita torneo mi sobrina quatroçientos reales e ponganse a çenso hasta que tomen estado de casadas o monjas o veatas.

yten mando que mi padre fray pedro de baldes que se den luego que yo muera veynte ducados para lo que el quisiere y es mi voluntad que no le quiten nada dellos pues conozco que yo e mi marido le debemos mucha mas quenta.

(A continuación siguen los habituales formulismos que indican que deben pagarse todas las deudas para finalmente instituir como universal heredero al monasterio de la Victoria de Madrid).

Yten mando...que hagan traer y traigan mi padre confesor y los demas albaçeas que yo nombrare las bulas de san juan de letran y todas las demas gracias y perdones que se ganan todo el año en el espital de la corte del rey don felipe las quales pidan a su santidad para la capilla...

Yten mando e declaro que dexo por patrones y subcesores en la capilla que yo tengo ... al dotor cespedes medico andante en corte y a doña ana de espinosa su muger a los quales nombro por patrones...

Yten declaro que de los dineros que yo di a la señora doña ana de espinosa... tengo reçebidos los reales y solo resta los doçientos ducados... mando que se cobren dellos.

(Siguen a continuación mandas piadosas a la cofradía de la Soledad y Angustias y a diferentes hospitales, de la corte, de Antón Martín, de la Paz, de la Pasión y de los Caballeros, a las monjas de Vallecas y al monasterio de san Francisco por misas que le debe)

Yten mando que alonso pardo le paguen el paño que dio para el luto y almohadas lo que el dixere.

Yten declaro que luis hurtado abia de dar doçientos ducados de çiertos salarios corridos que se debian a gaspar vezerra mi marido y estos doçientos ducados estan en poder de santoyo el pagador y mas lo corrido.

Yten declaro que Juan Beçerra tuvo çiertos dineros por gastar quando mi marido murio mando que le tomen quenta de lo que justamente hubiere gastado y lo que le alcançaren mando que se cobre del...

nombro por mis testamentarios... a los señores dotor cespedes medico de su magestad e a fray pedro de baldes fraile del monasterio de la vitoria desta villa de madrid y al guardian de san francisco desta villa de madrid y a hurbina pintor vezino desta villa de madrid...

(Siguen a continuación formulismos respecto a la anulación de cualquier otro testamento anterior).

... en la villa de madrid a primero dia del mes de junio de mil e quinientos y sesenta y ocho años testigos que fueron presentes... francisco de ampuero vecino desta villa y pedro de soto correo de su magestad e niculas sanguino natural de madrigal y bartolome hernandez ensamblador andante en corte y juan de avalos vezino de la villa de sant asensio estante en esta villa... (Firman los testigos por no saber hacerlo la otorgante).

$2^{\circ}$ Codicilo de Paula Velázquez, Madrid, 13 de diciembre de 1568 (AHPM, protocolos de Diego Méndez, 1568, $n^{\circ}$ 387). (Traslado en el AHPV, protocolos de Francisco del Torneo, 1570, $n^{\circ} 4520$, Tordesillas, fols. 506, 507).

En la villa de madrid a treze dias del mes de diciembre año de mil y quinientos y sesenta y ocho años... parescio presente paula belazquez biuda muger que fue de gaspar bezerra pintor de su magestad defunto estante en esta corte de su magestad estando enferma... e dixo que ella obo e tiene hecho su testamento e postrimera voluntad ante el presente escrivano el qual manda lo que es su ultima voluntad donde dexa por herederos al monasterio 
de nuestra señora de la vitoria desta villa de madrid frailes y convento del... y lo que tocare a lo aqui contenido se cumpla por via de codiçilio lo que es lo siguiente:

manda que en lo que toca a los albazeas que tiene nombrados en su testamento que solamente sean sus albazeas el padre fray pedro de baldes su confesor y el doctor cespedes medico...

yten en lo que toca a la edificacion de la capilla que tiene en el monasterio de nuestra señora de la vitoria desta villa donde se manda enterrar manda que se haga todo ello a la voluntad y parecer del padre fray pedro de baldes su confesor con que no se tome otro parecer ninguno por quanto el y la dicha paula belazquez y gaspar bezerra su marido lo tenian traçado y comunicado lo que se ha de hazer y como y en que manera y lo que se a de pintar en la dicha capilla lo haga micer rromulo pintor haziendo con el dicho fray pedro de baldes escritura de lo que se le a de dar y lo que se ha de hazer.

yten dixo que se declaren y aclaren las quentas que hay entre gaspar bezerra su marido y juan bezerra su hermano sobre lo que hay entre ellos conforme a la clausula del testamento del dicho gaspar becerra su marido y en lo tocante a las quentas de juan llorente mercader.

yten manda que en lo que toca a mariquita su sobrina el padre fray pedro de baldes la ponga donde mejor convenga para su rremedio para que sepa labrar y coser y servir...

yten manda que dominga la negra y su hija lucrecia se vendan en esta manera que la pongan en precio y por el precio que dieren se de a catalina de valdes estante en esta villa la qual conoze muy bien mi confesor vendiendola por el mayor precio que se hallare por ella, no se venda la chiquilla negrilla.

yten declaro que en poder de alonso pardo rropero ay y dio a un corredor... treynta botones de horo con perlas y una corneta de oro con tres perlas y un joyel de cuentas y un jarro de plata mando que se le pida o se cobre dellos y se le pague lo que sabe mi padre confesor que se le debe.

yten declaro que le deve manuel albarez entallador portugues setenta rreales que le empresto su marido manda que los cobren del.

yten declaro que el secretario de la princesa tomo un troço de machon de pino para los rretablos colaterales de la princesa que valia seys ducados que se cobre del y asimismo se cobre del el dorador de las puertas que estan puestas en el rretablo de la princesa asimysmo se deve las traças y monteas quel dicho su marido hizo para los rretablos colaterales que se cobre todo y se aga quenta si se deve mas y declaro que en poder de gironimo vazquez pintor vecino de valladolid estan todos los modelos que su marido truxo de ytalia que con carta de execucion se cobren del y de los otros donde estubieren.

yten manda que las quentas que su marido y ella an tenido con el bachiller torneo su primo en tordesillas se haga quenta con el y se acaben y por lo que jurare el dicho bachiller torneo se concluyan y se acaben y el que debiere pague.

yten declaro que en astorga le debian a su marido y se le deben çien ducados por escritura mando que se cobren.

yten declaro que se cobren çinquenta ducados de la marquesa de astorga que se deven.

yten manda que la traça de rruyseco para un rretablo esta en esta villa y ella la tiene la qual llebe un pariente suyo o la llebe el bachiller torneo o otro pariente y la lleben a rruyseco y si la quisieren que me lo paguen lo que baliere por vista de ofiçiales y se cobren.

yten declaro que la demanda que tiene puesta gaspar de hoyos no se le deve cosa ninguna de lo que pide.

manda que se paguen todas las deudas (siguen diferentes formulismos, indicando que lo único que está pendiente son las cuentas con juan llorente, juan becerra y alonso pardo).

(Los testigos son Juan Becerra, Baltasar Torneo, fray Diego de Vera, Domingo de Murrieta y Juan Guerra, vecinos de Madrid).

Cuentas entre el bachiller Pedro del Torneo, vecino de Tordesillas y primo de Paula Velázquez, con Gaspar Becerra y su esposa, para satisfacer al monasterio de la Victoria de Madrid, heredero del matrimonio. 29 de abril de 1570 (AHPV, protocolos de Francisco del Torneo, 1570, $n^{\circ}$ 4520, Tordesillas, fols. 488-493).

Las cuentas se inician con una presentación de los motivos que las ocasionan, como consecuencia del codicilo de Paula Velázquez que manda se pidan al bachiller Pedro del Torneo para arreglar la herencia con el monasterio de la Victoria.

La relación se inicia con los ingresos que el bachiller Torneo ha recibido de los negocios de Becerra y su mujer de los que él se encargaba. Se trata del cobro de censos, uno con Francisco Diez, vecino de Peñaranda y otro con Francisca de Mercado, vecina de Medina del Campo (cuyos beneficios desde el 6 de mayo del año 64 al 69 está en poder del dicho bachiller). A ello hay que unir el cobro de 80 ducados que «cobro por el dicho gaspar vezerra en medina del campo de un cambio por virtud de una cedula que le enbio desde madrid de la prinzesa». 
También cobró 80 ducados en Valladolid de «Urones clérigo y canonigo en la iglesia mayor por una obligacion que le enbio».

Los descargos que había hecho Pedro del Torneo en nombre de Becerra y su mujer aportan más datos. Comienza por anotar los gastos generados por la compra del censo de Medina y el correspondiente pago de las alcabalas, continuando con otras noticias:

yten que pago a xeronimo vazquez vecino de valladolid por mando del dicho becerra por su carta duçientos y sesenta y seys reales que montan... mill y quarenta y quatro maravedis mostro carta de pago y la carta de becerra.

yten que pago a gaspar de hoyos por mando del dicho becerra y por su carta cien reales mostro la carta y conocimiento.

yten que dio antonio vazquez por mando del dicho becerra y por su carta veynte ducados mostro carta como los reales.

yten que dio al dicho gaspar becerra quando vino al retablo de Rioseco çien reales que le pidio.

yten que dio a la señora paula velazquez quando vino de astorga para yr al pardo con su marido duçientos reales.

yten que dio a baltasar del torneo su criado quando vino de astorga para yr a madrid quatro ducados.

yten dio por descargo que gasto con el dicho baltasar y el dicho bachiller Torneo y un moço y tres cabalgaduras en yr a llebar dos cartas de su magestad y a tratar un negocio con el obispo y cabildo de astorga sobre el Retablo los quales se ocuparon quinze dias porque allegaron a villafranca en galicia para ablar al obispo y gasto cien reales.

yten que gasto en medina del campo en yr a comprar el dicho censo dos o tres veces y en lo que dio al escribano y corredores treinta reales reales.

yten que gasto en yr a peñaranda dos veçes a cobrar el dicho dinero el y dos cabalgaduras y un moço treinta

yten que gasto en valladolid en cobrar los dineros de urones en el pleito que traxo con el y en quatro dias questubo alla mil y ciento y veinte dos.

yten que gasto en cobrar los dineros del cambio en medina del campo...

yten que gasto el y un moço y dos cabalgaduras en yr a peñaranda a cobrar çien ducados quel dicho francisco diez debia al dicho gaspar becerra...

yten que dio a ventura del torneo por mando del dicho becerra dineros y una cabalgadura para yr a Rioseco con ciertas cartas suyas sobre el Retablo...

yten que el dicho ventura del torneo a madrid que le enbio a llamar la dicha paula velazquez y gasto en el dicho camino con la cabalgadura...

yten que compro un frontal para nuestra señora de tordesillas por mando del dicho becerra y su muger y costaron çinco baras de brocatel a veinte y siete reales que montan quatro mill y quatrocientos y nobenta reales.

costaron tres baras de terciopelo carmesi a treynta y çinco reales que montan tres mill y quatrocientos y setenta.

costo el aforro un ducado y la seda siete honças y hechura y allego todo a dos mill y setenta y çinco maravedis.

comprose en Valladolid el aparejo para el dicho frontal y diose a hacer en el y gasto el dicho bachiller torneo en irle a comprar y en darle a hacer y en enbiar despues por el quince reales...

yten dio por descargo el dicho bachiller torneo que se ocupo su persona y una mula y un moço con otra cabalgadura en serviçio del dicho gaspar becerra y su muger y en lo arriba contenido quarenta y dos dias segun dio por un memorial firmado de su nombre y diosele por su trabajo y alquiler de las dichas cabalgaduras y mozo quarenta y dos ducados que vale a un cada dia.

yten dio por descargo que paula velazquez ynbio a ventura del torneo quando vino de astorga a buscar un mozo de gaspar bezerra el qual iba haçia astorga con cartas para la dicha paula velazquez y se ocupó dos días que le dio para el gasto doce reales.

(Las cuentas finalizan con lo que adeuda el monasterio al bachiller Torneo, pagadero de la herencia de Paula Velázquez, después de lo que se ha visto en la relación. Da por descargo 215677 maravedís. Le han de pagar al bachiller 11405 maravedis. Siguen una serie de formulismos en que el bachiller jura que ha dicho la verdad en las cuentas. Pide que el representante del monasterio de la Victoria, fray Juan Martínez le de carta de pago de lo dicho y presente la documentación oportuna que lo acredite como heredero de Paula Velázquez, lo que genera el traslado de la documentación testamentaria. El fraile da las cuentas por buenas y dice que pagarán al bachiller lo que le deben. A partir de ese momento el monasterio se encargará de cobrar los censos que cobraba el bachiller Torneo como heredero de Paula Velázquez. Los censos se habían formalizado ante Payo Cuello y Martín Alonso, de Medina del Campo, sin que se indique la fecha). Los testigos del documento son Ventura del Torneo, Hernando Velez y Diego Cedillo, vecinos de Tordesillas. 
吾

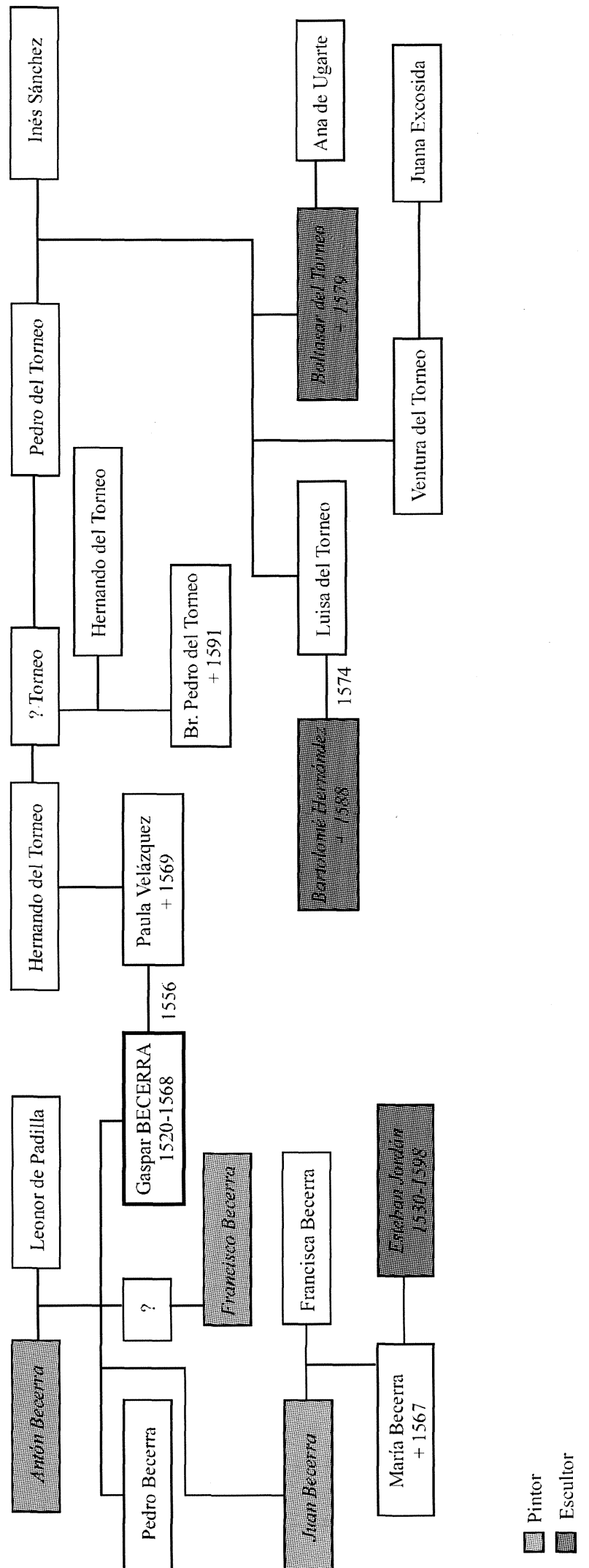

